\title{
War Metaphors in Chinese Digital Media Coverage of COVID-19
}

\author{
ZHENG YANG, Soochow University
}

\begin{abstract}
War metaphors have been found to be the most frequently used metaphors for conceptualizing diseases, epidemic and medicine. During the COVID-19 epidemic, war metaphors have been found to be widely used in both online and offline coverage. This study mainly focuses on how war metaphors were used in Chinese social media coverage about the COVID-19 epidemic. Using the method of semantic network analysis and the account of The People's Daily on the Chinese social media platform Weibo as an example, the findings show that war metaphors are widely used in the digital coverage of COVID-19. Compared with defensive metaphors and war process metaphors, offensive war metaphors are appearing much more frequently in digital coverage, and often with the use of national collective subjects. These two characteristics highlight how digital coverage uses militarized metaphors to mobilize and inspire enthusiasm among the Chinese people, and to strengthen the Chinese government's control in dealing with the COVID-19 epidemic.
\end{abstract}

\section{KEYWORDS:}

COVID-19; Digital Media; War Metaphors; Social Media; The People's Daily

\section{Introduction}

As a language tool to help people understand the external world and express our inner feelings, metaphors exist widely around people's daily lives (Lakoff \& Johnson, 1980). Many scholars have pointed out that coverage of epidemics often relies on war metaphors, and such metaphors may have both positive and negative impact on public perceptions and responses to such epidemics (Wallis \& Nerlich, 2005; Larson, Nerlich $\&$ Wallis, 2005; Nie et al., 2016). On the one hand, war metaphors are thought to help boost public morale and integrate resources to deal with emergencies more intensively, but on the other hand, excessive use of way metaphors has also been found to have the potential to cause unnecessary public panic (Wallis \& Nerlich, 2005; Nie et al., 2016; Nie, 2017). China had seen a decline in the use of war metaphors in disease coverage before the COVID-19 outbreak (Yang, 2020; Sun, 2020). But during the outbreak, some Chinese scholars still found that war metaphors exist in a large proportion of COVID19 coverage in traditional Chinese media, such as newspapers and television news (Sun, 
2020). Reflecting on why war metaphors are widely used in the coverage of diseases, especially epidemics, some scholars believe that this stems from the long-standing 'biomedical' model for understanding health, and the binary opposition relationship between people and diseases (Nie et al., 2016; Nie, 2017). Relying on such war metaphors, it seems that people can deal with the relationship between disease and humans more concisely, that is, after simply 'eliminating' the disease, humans can 'reoccupy' health (Li, 2014; Jia, 2015). However, there has been little research about the use of war metaphors in Chinese digital journalism, especially on social media platforms. This study uses the account of The People's Daily, the biggest Chinese official newspaper, on Weibo, the biggest Chinese social media platform, as an example to explore the usage and characteristics of war metaphors in Chinese COVID-19 digital coverage. The findings of this research could help to gain a deeper and more comprehensive understanding of the reliance on war metaphors and their use in Chinese digital journalism during the epidemic in the rapidly developing Chinese digital media environment. Furthermore, combined with the understanding of the potential positive and negative effects of war metaphors for people to deal with sudden infectious diseases, the research findings could also help better understand how to use communication tools on digital media platforms to face future instances of sudden outbreaks of infectious diseases like COVID-19.

\section{War Metaphors, Disease Coverage and Digital Platforms}

Language has always been regarded as a powerful tool in health and the medicine field (Harrington, 2012, p.411). Metaphors play a non-negligible role when used as a language tool in such field (Hanne \& Hawken, 2007; Harrington, 2012). According to Lakoff and Johnson (1980, p.3), a metaphor is a figure of speech that describes an object or action in a way that is not literally true but helps to explain an idea or make a comparison. Metaphors are considered not only to have cognitive functions, but also to participate in the construction of social existence (Nie et al., 2017). As a cultural and linguistic tool for conceptualizing diseases, metaphors have always had an effect on health communication in both doctor-patient interactions and media coverage (Fuks, 2009; Neilson, 2015; Wallis \& Nerlich, 2005). Since humans began trying to understand the concepts of disease and health, metaphors have been used to help people understand complex, sometimes invisible, pathology, disease processes and treatment process (Annas, 1995; Neilson, 2015). Many studies have shown that the use of metaphors to describe diseases could help people to familiarize themselves with the concepts and experiences of diseases, and further effectively help them to understand the symptoms, diseases and treatment processes, and also produce patient-centred healthcare (Gibbs \& Franks, 2002; Reisfield \& Wilson, 2004; Casarett et al., 2010; Harrington, 2012). However, some studies still show that using inappropriate medical metaphors could also cause the public to have a wrong understanding and attitude 
towards the disease, which also has a negative impact on the treatment process of the disease (Jobst et al., 1999; Reisfield \& Wilson, 2004; Sim, 2008; Harrington, 2012). The media environment, especially the rapidly developing and influential digital media, may also magnify both the positive and negative impacts of metaphors on the public's perception of health and disease (Weinstein, 2003). Therefore, exploring and understanding the rhetorical features of the metaphors for health and diseases in the media environment could help us better control the influence of those metaphors. Especially in this special period of the global outbreak of the COVID-19 epidemic, understanding the metaphors used in the coverage of COVID-19 could greatly help us better respond to the epidemic in both sociocultural and medical dimensions.

Among all the metaphors used in disease expressions, especially in epidemic expressions, war metaphors have been found to be the most frequently used (Semino, 2008). War terms, such as 'enemy', 'attack', 'army' and 'front' have been found to be widely used to refer to diseases, patients, doctors, and responses to disease, especially during the epidemic outbreak (Wiggins, 2012). For instance, during the SARS outbreak, many war concepts were found to be widely used in both official coverage and public discussions, such as 'fight against the SARS epidemic', 'win the final victory in the battle against SARS', and the 'soldiers fighting on the front line of the battle against SARS' (Wallis \& Nerlich, 2005). The widespread application of such war metaphors in the expression of diseases, especially infectious diseases, is considered to be closely related to the popularity of modern medical theories, especially bacterial theories. People tend to regard viruses that 'invade' the human body and cause illnesses as foreign invaders, and their own immune mechanisms as 'defenders'; The illness-process itself is just a battle between the virus as the 'invader' and immune system as the 'defender' (Baehr, 2006). Such an idea is similar to the traditional Chinese medicine idea that the cause of human diseases is attributed to 'external evil (Waixie)'. Therefore, under the dual effects of traditional Chinese medicine theories and the newly absorbed Western modern medical theories, the war metaphors have been also found to be widely used in the expression of diseases in the Chinese context (Jia, 2015; Nie, 2017).

However, as mentioned above, improper use of metaphors may have a negative impact on people's understanding and response to diseases. Although some studies have shown that using war metaphors can help strengthen the courage of patients facing disease, and also help society to coordinate resources, especially during the sudden epidemic outbreaks like SARS and currently, COVID-19 (Annas, 1995; Casarett et al., 2010; Fuks, 2009; Harrington, 2012; Nie, 1996; 2017), excessive use of war metaphors could also bring about some negative influences, such as causing patients to panic, strengthening the masculine, paternalistic image of medicine, weakening patients' discursive power, overemphasizing patients' obedience to medical authorities, and undermining patients' narratives of their personal experiences with disease (Jobst et al., 1999; Reisfield \& Wilson, 2004; Sim, 2008; Harrington, 2012). This is because war metaphors tend to describe the relationship between the patient and the disease as a 
dualistic relationship of 'Life or Death'. Humans and diseases cannot coexist in this metaphorical system (Radley, 2002; Cockerham, 2017). Some scholars even point out that "the ideological filter encased within the war metaphor is 'militarism', defined as a set of beliefs and values that stress the use of force and domination as appropriate means to solve problems and gain political power" (Kraska \& Kappeler, 1997, p.2).

Although there is no direct evidence that the war metaphor in the disease narrative will directly lead to the prevalence of 'militarism', according to Parsi (2016), excessive use of war metaphors is indeed more likely to cause further power inequality between those who control the discourse power in disease narratives, such as health policy maker or medical authority, and vulnerable groups, such as patients. Therefore, many current studies of disease narratives, especially those on the experience and narrative of chronic patients, indicate that humans should view disease from a more harmonious rather than opposite perspective, with richer metaphors (McCartney, 2014; Parikh et al., 2015; Wiggins, 2012). Some researchers even propose to use metaphors such as 'journey' to replace the important position of 'war' metaphors in disease expression and narrative (Semino, 2017).

Most studies mentioned above have applied qualitative research methods, such as discourse analysis, in the Western context. Few studies have used quantitative methods to examine the use of war metaphors in the Chinese context. And most existing research on metaphors of disease or epidemics also only focuses on traditional media content, especially print media such as newspaper and magazines (for example: Wallis \& Nerlich, 2005; Kirkman, 2008; Kothari, 2016). Ample content space makes it easier for metaphors with cultural significances to be produced and represented in print media (Stephen et al., 2018). But in the digital media environment, which has quite different characteristics and affordances, current research on whether those metaphors are still as prominent as in the traditional media environment is still very limited. But some scholars have already pointed out that even in cases where the content space is very limited, rhetorical means, such as metaphors, have also been widely used in text expression and communication on social media platforms (Brems et al., 2017; Pihlaja, 2017). Digital coverage of disease and epidemics and discussion about illness, health and caring on social media platforms is believed to rely heavily on narratives or storytelling (Hardey, 2002; Orgad, 2005; Bers, 2009), and metaphors have been widely used in these narratives (Brems et al., 2017; Pihlaja, 2017). Therefore, although there is little empirical research analysing the widespread existence and expression characteristics of war metaphors in digital coverage about diseases and epidemic especially on social media platforms - according to the above review (such as Bers, 2009; Brems et al., 2017; Pihlaja, 2017), it can be inferred that war metaphors are indeed widely used in electronic news and social media discussions about diseases and epidemics. Indeed, some qualitative research studies have already pointed out that war metaphors have appeared in descriptions of COVID-19 (although maybe not in the social media environment) and have profoundly affected understanding of, and responses to, COVID-19 (Gillis, 2020). However, as mentioned earlier, these studies are 
almost all based on the Western context. What is the situation in the Chinese context? Are there extensive war metaphors for the COVID-19 epidemic in the Chinese environment, especially in digital coverage of COVID-19 on social media platforms? If so, what are the rhetorical and expressive characteristics of these war metaphors for COVID-19? And what positive or negative impacts might these war metaphors have on China's response to the COVID-19 epidemic? These are the research questions that this study aims to explore.

\section{Methodology and Data Collection}

As mentioned above, most previous studies on war metaphors used in coverage of disease or epidemics have been based on qualitative research methods, focusing on the traditional media environment, such as rhetorical analysis and frame analysis (Annas, 1995; Fuks, 2009; Casarett et al., 2010; McCartney, 2014; Parikh et al., 2015). The research on war metaphors used in digital coverage of disease or epidemics in the digital media environment, especially on social media platforms, is rare, as is quantitative research methods based on big Internet data. To make up for these shortcomings and to explore more comprehensively the characteristics of war metaphors used in digital coverage of the COVID-19 epidemic on Chinese social media platforms, this study uses the method of semantic network analysis.

This study analysed all the digital coverage of COVID-19 published by the official Weibo account of The People's Daily from $1^{\text {st }}$ December 2019 to $27^{\text {th }}$ February 2020. The People's Daily (Renmin Ribao) is the largest newspaper in China with a circulation of three million (Wu, 1994). On Weibo, the official account of The People's Daily is also the traditional media account with the largest number of followers and the most influence (Xu, 2014). In April 2020, The People's Daily had more than 1,200 million followers on Weibo. The daily average number of posts published by The People's Daily account during the COVID-19 epidemic on Weibo was more than 200, and it has become the most important online resource for the Chinese public to obtain information about COVID-19. The epidemic broke out in China in late November and early December 2019 and reached a peak around February 2020. Thus, the study uses data published from December to February as analysis samples. The three-month period should provide sufficient data for a robust analysis.

Using Python software to create a web crawler, 11,362,502 posts were collected via six keyword queries ${ }^{1}$ based on the top trending coronavirus stories on Weibo. By mining all the content published by the official account of The People's Daily on Weibo, 16,178 posts were screened out as the final analysis database. Most of those posts are original posts $(12,619,78 \%)$; only $22 \%$ are retweets with comments $(3,559)$. Since those retweets with comments also convey important information about the COVID-19 epidemic and reveals The People's Daily official account as China's national official

1 新冠”、“新冠肺炎”、“新冠疫情”、“新冠病毒”、“新型冠状肺炎”、“新型冠状病毒” 
social media account's attitude towards selecting information about COVID-19, it also has a social function as digital coverage. Thus, those retweets with comments attached were also included in the database for analysis.

This study uses the method of semantic analysis to explore whether war metaphors are obvious in the digital coverage of COVID-19 on Weibo and, if so, how the characteristics of such war metaphors are used in this digital coverage. Semantic network analysis is a research approach for visual text analytics using methods of network analysis to gain quantitative and qualitative insights. Through the cooccurrence of words, it presents a large amount of text in the form of a network, so that researchers can discover the semantic features of the text (Drieger, 2013). The traditional qualitative research methods for metaphor analysis based on in-depth reading are not well adapted to the big data characteristics of digital media environment. Therefore, the semantic network analysis of presenting a large amount of text data in a quantitative network form is deemed most suitable for the purposes of this research. The study involves the flowing steps:

(1) Data collection from Weibo, as discussed above.

(2) Word segmentation: Chinese word segmentation is the task of splitting Chinese text (a sequence of Chinese characters) into words. Different from the language of English, where the words in a sentence are naturally segmented by 'spaces', the language of Chinese is directly composed of continuous, uninterrupted Chinese characters. Therefore, the difficulties to determine how many individual words constitute a Chinese sentence has become a major problem in Chinese computational linguistics analysis. And it just so happens that metaphors, especially war metaphors in Chinese, often exist in the form of words. Therefore, if we want to use computational linguistic methods such as semantic network analysis to study war metaphors in Chinese, we first need to segment the Chinese text we have collected. To achieve this, Jieba, a Chinese text segmentation module based on Python, was used to conduct such tasks (Liu et al., 2018).

(3) Semantic network analysis: After word segmentation, all the sample texts are processed into the analyzable data in sentence units consisting of divided words. Further, by deleting some words that appear frequently in the database but have no practical meanings, such as conjunctions, function words, modal particles, etc., the final analysis text data is obtained. All the final data has been imported into the network and visualization analysis software: Gephi 0.9.2 to get the final semantic network. In the semantic network, each single word will be regarded as a node, and two words 
appearing together in a sentence will be regarded as a relationship (line). Thus, an undirected network based on word co-occurrence in all the posts about COVID-19 epidemic published by The People's Daily on Weibo from $1^{\text {st }}$ December 2019 to $27^{\text {th }}$ February 2020 could be constructed.

\section{Analysis and Findings}

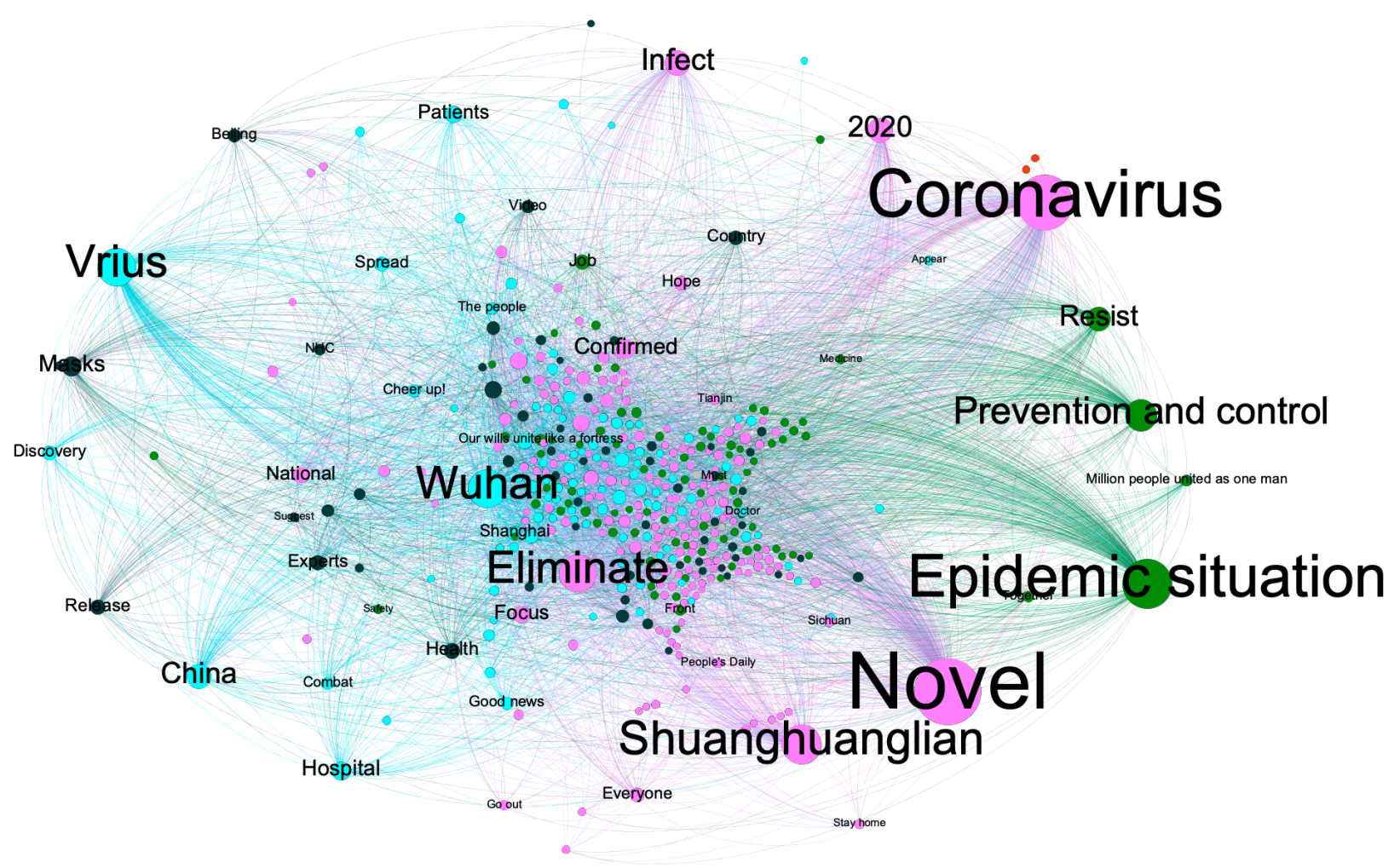

Figure 1. Visualization result of semantic network analysis

Through the semantic analysis of all the posts about COVID-19 published by The People's Daily on Weibo during the three-month sample period, a semantic network was constructed (Figure 1). In the network, each node represents one word. Due to the huge number of nodes (more than 20,000), the nodes with a degree of less than 50 were filtered out, which means the centrality of the words represented by those nodes in the network is less than 50 (i.e., it is not very significant in the whole semantic network). The sizes of the nodes in this network represent the degree of each node. Only the top 50 nodes with the highest degree have been shown with labels. The colours here indicate clusters, which means nodes with the same colour tend to appear in the same or similar sentences. 
Through the visualization result of semantic network analysis (Figure 1), some war terms are clear in this network, such as 'eliminate' (Xiaomie, 消灭), 'prevention and control' (Fangkong 防控), 'resist' (Diyu 抵御), 'combat' (Zhandou 战斗) and 'front' (Zhanxian 战线). Since only the top 50 nodes with the highest degree have been shown with labels in this network, the visible war words in this semantic network are thus widely used in the digital coverage of COVID-19 by The People's Daily on Weibo. For instance, in the following example, The People's Daily described the management and response to COVID-19 as 'the front of fighting with the epidemic', and a policeman who died at work responding to COVID-19 is also described as a battle hero (Figure 2; the face of the policeman has been obscured).

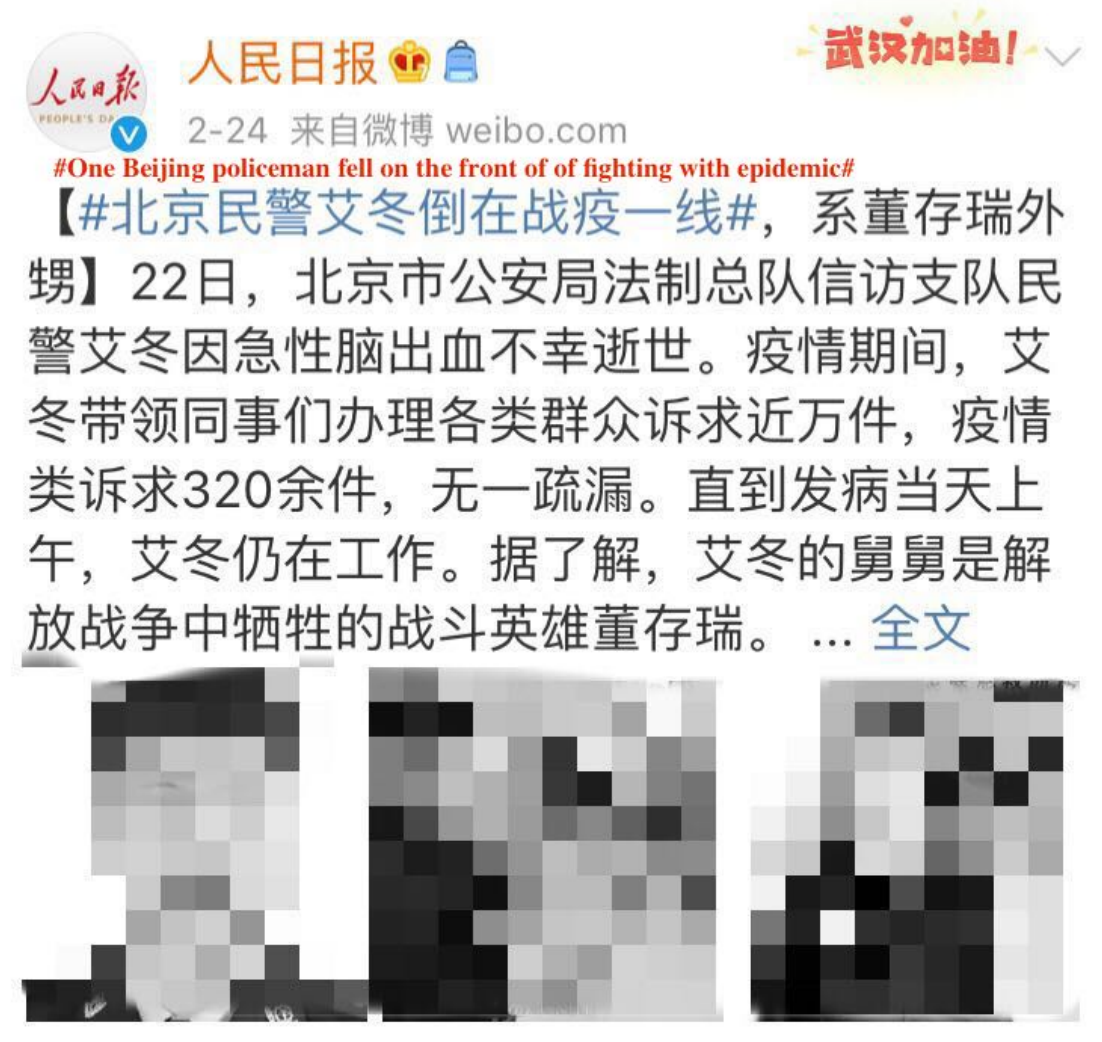

Figure 2. Example of digital coverage with war metaphors by The People's Daily on Weibo

Except for these individual war words which are similarly used in war metaphors for medicine in a Western context (Fuks, 2010), there are still some war expressions with Chinese characteristics and proverbial nature that are widely used by The People's Daily in reporting about COVID-19 on Weibo, such as 'our wills unite like a fortress' (Zhongzhichengcheng 众志成城) and 'million people united as one man' (Wanzhongyixin 万众一心). These two idioms are believed to originate from ancient 
battlefields and are considered to be the most commonly used militarized idioms in China today to inspire people to have a positive attitude towards a particular subject, also called 'morale' (Shiqi 士气) (Shi et al., 1982). Similarly, on Weibo, The People's Daily also frequently used these two war idioms in its digital coverage of COVID-19 and related matters. For instance: "we must resist this battle like million people united as one man, so that we can win the final victory" (The People's Daily, 01/02/2020) and "the Chinese people's wills unite like a fortress and have achieved major strategic results in the fight against the COVID-19 epidemic" (The People's Daily, 25/02/2020).

The analysis above, based on the visualization results, shows that war metaphors were widely used in the digital coverage of COVID-19 by The People's Daily on Weibo. To obtain more accurate analysis results, the degree of the node and weight of edges is used as an indicator to list the 50 words with the highest degree. Table 1 shows that, in the topic of 50 words with highest degree, there are eight words (in italics and bold) with obvious militarized language features. Among all language possibilities, war language, as a special rhetoric technique, accounts for $16 \%$. This also shows that as a special rhetorical technique, war metaphor occupies a very obvious proportion in digital coverage of COVID-19 which could have multiple rhetorical possibilities. At least as far as the types of metaphors are concerned, no other metaphor types with a higher proportion appear among the 50 words in the highest degree. This indicates that war metaphors are indeed widespread in the digital coverage of COVID-19 by The People's Daily on Weibo.

Table 1. Top 50 words with highest node degree in the semantic network

\begin{tabular}{|c|c|c|c|c|c|}
\hline Word & Degree & Word & Degree & Word & Degree \\
\hline Health & 2501 & Wuhan & 246 & Confirmed & 150 \\
\hline Shuanghuanlian & 1461 & Combat & 244 & Stay home & 143 \\
\hline Coronavirus & 1148 & Country & 238 & Go out & 139 \\
\hline Novel & 733 & $\begin{array}{l}\text { Prevention and } \\
\text { control }\end{array}$ & 235 & Sichuan & 136 \\
\hline 2020 & 645 & Infect & 235 & Patients & 136 \\
\hline China & 493 & Experts & 235 & Must & 136 \\
\hline Epidemic situation & 427 & Shanghai & 218 & People's Daily & 132 \\
\hline
\end{tabular}




\begin{tabular}{|c|c|c|c|c|c|}
\hline Masks & 381 & Cheer up & 211 & Tianjin & 128 \\
\hline Eliminate & 365 & Beijing & 202 & Conquer & 125 \\
\hline$\underline{\text { National }}$ & 352 & Virus & 194 & Battle & 125 \\
\hline Focus & 337 & Together & 187 & Appear & 125 \\
\hline Hospital & 326 & Spread & 187 & $\mathrm{NHC}$ & 123 \\
\hline Job & 297 & $\begin{array}{c}\text { Million people } \\
\begin{array}{c}\text { united as one } \\
\text { man }\end{array}\end{array}$ & 187 & Medicine & 123 \\
\hline Everyone & 297 & The people & 176 & Video & 121 \\
\hline Release & 290 & Discovery & 176 & Safety & 121 \\
\hline $\begin{array}{l}\text { Our wills unite } \\
\text { like a fortress }\end{array}$ & 273 & Front & 165 & The public & 119 \\
\hline Hope & 264 & Good news & 150 & & \\
\hline
\end{tabular}

\section{Aggressively offensive metaphors in Chinese digital coverage of COVID-19}

According to some Chinese scholars, Chinese war metaphors can be divided into three categories: offensive metaphors (such as eliminate, conquer, battle, resist control and combat); defensive metaphors (such as defend, defence, resist, and guard); and war process metaphors (such as solider, quartermaster, strategy, tactics, victory, morale and front). Among these three categories, offensive and defensive metaphors were more commonly used in the representation of diseases in China (Jia, 2015; Yang \& Dong, 2017). Among the eight most used war words shown in Table 1, four are offensive war metaphors, two could be defined as defensive war metaphors, and two could be identified as war process metaphors (Table 2).

Table 2. Different categories of war metaphors used in digital coverage of COVID-19 by The People's Daily on Weibo 


\begin{tabular}{|c|c|c|c|}
\hline \multirow{4}{*}{$\begin{array}{l}\text { Offensive war } \\
\text { metaphors }\end{array}$} & Eliminate & 365 & \multirow{4}{*}{859} \\
\hline & Combat & 244 & \\
\hline & Conquer & 125 & \\
\hline & Battle & 125 & \\
\hline \multirow{2}{*}{$\begin{array}{l}\text { Defensive war } \\
\text { metaphors }\end{array}$} & Our wills unite like a fortress & 273 & \multirow{2}{*}{508} \\
\hline & Prevention and control & 235 & \\
\hline \multirow{2}{*}{ War process metaphors } & $\begin{array}{l}\text { Million people united as one } \\
\text { man }\end{array}$ & 187 & \multirow{2}{*}{352} \\
\hline & Front & 165 & \\
\hline
\end{tabular}

Table 2 shows that offensive war metaphors not only occupy a prominent position in the number of words but are also higher than the other two categories of war metaphors in the sum of node degrees. This indicates that offensive war metaphors are used more frequently in the digital coverage of COVID-19 by The People's Daily on Weibo than defensive war metaphors and war process metaphors. The tendency to use offensive words in war metaphors could be related to Chinese people's understandings of disease. As mentioned above, according to the traditional Chinese medical theories, diseases are caused by external substance (Waixie) invading the human body. Therefore, the process of curing diseases is the struggle between the righteous energy (Zhengqi) in the body and such external substance (Waixie). As long as the righteous energy (Zhengqi) overcomes the external substance (Waixie) and harmony (Hexie) overcomes the disorder (Butiao), the human body will be restored to health (Veith, 1997). Such understanding is further combined with the Western medical concepts introduced into China in modern times, especially with the bacteria theory. It is believed that only by "repelling" and "eliminating" viruses and external substance (Waixie) that invade the human body can humans overcome the diseases, especially the infectious ones (Rin, 1965). This idea was evident during the outbreak of COVID-19 in China. Almost all coverage of COVID-19 tends to portray the virus as an 'evil' virus that invades the human body from the outside world (Shao \& Ye, 2020). Furthermore, because this virus may be related to the Chinese people's consumption of wild bats, many online discourses link the COVID-19 virus with the terrible image of bats and 'evil animal revenge' ${ }^{2}$.

\footnotetext{
2 Examples of such internet discourse include: https://baijiahao.baidu.com/s?id=1659047264175634903\&wfr=spider\&for $=$ pc (Title: COVID-19 is a means of revenge from nature) and http://k.sina.com.cn/article $6196100187 \quad 17150 \mathrm{fc} 5 \mathrm{~b} 00100 \mathrm{t} 6 \mathrm{ha} . \mathrm{html}$ (Title: During COVID-19 and Australian wildfires, bats all play an evil role, can humans eliminate them?)
} 
Offensive war metaphors are believed to have positive social effects in bringing together members of society, mobilizing their enthusiasm, and inspiring people to deal with a specific matter together. As a result, they are found to be widely used in coverage during the outbreak of sudden infectious diseases. In comparison, China's coverage of the SARS outbreak was found to have prominent offensive war metaphor features $(\mathrm{Li}$, 2014). Chinese scholars believe that these metaphors had positive social effects in mobilizing national strength and boosting the morale of the Chinese people to deal with SARS. In the contemporary Chinese situation, in which uniting a collective power against a demonized disease is emphasized, the coverage is also inclined towards an offensive rather than a defensive vocabulary in war metaphors related to the disease. But whether it still plays a positive social role as it did during the SARS outbreak requires more profound and long-term social research to determine.

\section{Collectivism and war metaphors in Chinese digital coverage of COVID-19}

From the semantic network and the top 50 words list, another phenomenon is clear: unifying and collectivizing terms referring to the united Chinese people are widely used in the digital coverage of COVID-19 by The People's Daily on Weibo, including 'national' (Quanguo 全国), 'everyone' (Meigeren 每个人), and 'the public' (Dazhong 大众) (Table 3). There are only two subjects referring to specific groups: experts and patients. According to the sum of node degree of the two different subject categories, the collective subjects referring to the people of the whole country dominated the mainstream. Some scholars note that, in war actions, regardless of the participants' original social identities, they take on the unified identity of 'fighter'. Therefore, in war terms, the collective expression of subjects such as 'the whole of us', 'all the people' and 'all nationals' are widely used (Hall, 1999). This is also significant in China when facing the COVID-19 outbreak. When war metaphors are used, social identities are erased, and all subjects are considered part of a homogeneous unified collective (Cohen, 2011). Thus, during the outbreak of the COVID-19 epidemic in China, where the war metaphors are widely used in the Chinese digital coverage on Weibo, the subjects of most actions are collective, such as 'the public' and 'the people'.

Table 3. Different categories of subjects used in digital coverage of COVID-19 by The People's Daily on Weibo

\begin{tabular}{cccc}
\hline Subject categories & Words & Degree & Sum of Degree \\
\hline \multirow{3}{*}{ Collective subjects } & national & 352 & \\
\cline { 2 - 3 } & everyone & 297 & 1591 \\
\cline { 2 - 3 } & our & 273 & \\
\hline
\end{tabular}




\begin{tabular}{ccc}
\hline & together & 187 \\
\cline { 2 - 3 } & million people & 187 \\
\hline the people & 176 \\
\hline the public & 119 \\
\hline Specific subjects & experts & 235 \\
\hline & patients & 136 \\
\hline
\end{tabular}

The collective subjects widely used in the digital discourse of COVID-19 erase the differences between various groups of people facing the epidemic and instead give them a similar social role: 'warriors' or 'soldiers' fighting against the epidemic. For example: "China's fight against the COVID-19 epidemic is a miracle in the history of human struggle against the disease. This is a test for all the Chinese people and a battle for all the Chinese people" (The People's Daily, 27/02/2020). Applying a soldier's identity to all the Chinese people further transforms the government's advice on the behaviour of Chinese citizens facing the COVID-19 epidemic into a war order, such as insisting that they must 'stay home', must wear a 'mask' and never 'go out'.

In the present study, the relationship found between war metaphors and the collectivization of subjects used in the digital coverage of COVID-19 on Weibo points out that it is necessary for us to rethink the influence of war metaphors in how COVID19 is understood in the Chinese digital media environment. As discussed above, war metaphors have some positive social functions when dealing with diseases, especially epidemics: integrating social resources and encouraging public morale to cope with sudden diseases such as SARS, as well as the current COVID-19 epidemic (Annas, 1995; Fuks, 2009; Casarett et al., 2010; Harrington, 2012; Nie, 1990; 2016). Such social functions may be closely related to the use of collectivized subject pronouns. Nie et al. (2016) observed that "war metaphors for disease may help to enhance the morale of patients and health care professionals alike with respect to the healing process, especially when the problems involved are serious and life-threatening, and they may also help the whole society to mobilize human, economic, and social resources for healthcare and medical research to face sudden infectious diseases" (p.5). However, the over-emphasis on homogenous, collectivized subject pronouns in the influential digital coverages of COVID-19 on Weibo may also neglect the social identities and characteristics of the different Chinese groups to some extent and impose more social responsibility and collective social identities on the Chinese public facing the COVID19 epidemic.

\section{Discussion, Conclusion, and Limitations}


The findings from the analysis above show that war metaphors are widely used in the digital coverage of COVID-19 on Chinese social media, taking the account of The People's Daily on Weibo as an example. Compared with defensive metaphors and war process metaphors, offensive war metaphors more readily appear in this digital coverage, and further, often with the use of national collective subjects. These two characteristics of the use of war metaphor in the digital coverage of COVID-19 highlight the situation that such coverage aims to use militarized metaphors to mobilize and inspire the enthusiasm of the Chinese people across the country and strengthen the control of China's government in dealing with the epidemic. This is not just characteristic of China's coverage in the face of COVID-19 (Gillis, 2020; Craig, 2020; Jetly et al., 2020), but the metaphors used show some obvious Chinese national folklore characteristics, such as treating COVID-19 as an evil virus that invades the human body (Waixie), employing idioms with Chinese characteristics to strengthen the expression of these war metaphors.

As discussed at the beginning of this article, many studies on the use of war metaphors during the outbreaks of epidemics, such as SARS and COVID-19, have pointed out that those war metaphors can strengthen the courage of the public in the face of disease, and they can help society to coordinate resources in coping with such sudden outbreaks (Annas, 1995; Casarett et al., 2010; Fuks, 2009; Harrington, 2012; Nie, 1996; Nie et al., 2016; Gillis, 2020; Craig, 2020; Jetly et al., 2020). But we also need to reflect on some of the disadvantages that may be brought about by the excessive use of militarized metaphors. The over-reliance on militarized metaphors may cause the public to panic, strengthening the masculine, paternalistic image of medicine, weakening patients' discursive power, overemphasizing the public's obedience to medical authorities, and undermining the public's narratives of their personal experiences with disease (Jobst et al., 1999; Reisfield \& Wilson, 2004; Sim, 2008; Harrington, 2012). As this study mainly focused on quantitative network data, further studies are needed to explore the negative consequences that the excessive use of war metaphors may bring. For understanding metaphors and their socio-cultural functions, qualitative data can bring some deeper insights. Combining quantitative and qualitative methods in future studies could offer a more comprehensive understanding of the use of war metaphors in digital coverage of diseases.

To sum up, according to the semantic analysis in this study, the war metaphor has already become the most obvious and dominant rhetorical expression. Other types of metaphors are almost invisible in the semantic network. Many scholars have already emphasized that when facing some chronic diseases, a softer and harmonious symbiosis metaphor is needed to construct our relationship with disease, health and medical care, such as a 'journal metaphor' (Nie et al., 2016). In the face of COVID-19, China has already achieved an initial victory, and the relationship with COVID-19 is now no longer as extreme and intense as it was in early 2020. The Chinese people eagerly hope to return to normal daily life without strict 'militarized' control. Just as Zhang Wenhong, director of the Department of Infectious Diseases, Huashan Hospital, Fudan 
University (who was awarded a national commendation for his outstanding contributions in the face of the COVID-19 epidemic) said, in the long run, humans do not have the conditions to eliminate COVID-19. From the perspective of the whole of China and the wider world, there should be a state of symbiosis between the people and the COVID-19 virus (Zhang, 2020). Therefore, in the post-epidemic era, with the epidemic stabilizing, we need multiple metaphors other than just war metaphors - not only in China, but across the world - to help us cope with the new relationship between humans and COVID-19, which appears to be here to stay, and to help us rebuild a more harmonious symbiotic relationship between mankind and disease, health and nature.

\section{References}

Annas, G. J. (1995). Reframing the debate on health care reform by replacing our metaphors. The New England Journal of Medicine, 332(11), 744-747.

Baehr, P. (2006). Susan Sontag, battle language and the Hong Kong SARS outbreak of 2003. Economy and Society, 35(1), 42-64.

Bers, M. U. (2009). New media for new organs: A virtual community for pediatric post-transplant patients. Convergence, 15(4), 462-469.

Brems, C., Temmerman, M., Graham, T., \& Broersma, M. (2017). Personal branding on Twitter: How employed and freelance journalists stage themselves on social media. Digital Journalism, 5(4), 443-459.

Casarett, D., Pickard, A., Fishman, J. M., Alexander, S. C., Arnold, R. M., Pollak, K. I., \& Tulsky, J. A. (2010). Can metaphors and analogies improve communication with seriously ill patients? Journal of Palliative Medicine, 13(3), 255-260.

Cockerham, W. C. (2017). Medical sociology. Routledge.

Cohen, M. J. (2011). Is the UK preparing for 'war'? War metaphors, personal carbon allowances, and consumption rationing in historical perspective. Climatic Change, 104(2), 199-222.

Craig, D. (2020). Pandemic and its metaphors: Sontag revisited in the COVID19 era. European Journal of Cultural Studies, 1367549420938403.

Drieger, P. (2013). Semantic network analysis as a method for visual text analytics. Procedia-social and behavioral sciences, 79(2013), 4-17.

Flusberg, S. J., Matlock, T., \& Thibodeau, P. H. (2018). War metaphors in public discourse. Metaphor and Symbol, 33(1), 1-18.

Fuks, A. (2009). The war metaphors of modern medicine. The Meaning Management Challenge, 124, 57-68. 
Fuks, A. (2010). The war metaphors of modern medicine. In The Meaning Management Challenge: Making Sense of Health, Illness and Disease (pp. 55-68). Brill.

Gibbs Jr, R. W., \& Franks, H. (2002). Embodied metaphor in women's narratives about their experiences with cancer. Health Communication, 14(2), 139-165.

Gillis, M. (2020). Ventilators, missiles, doctors, troops... the justification of legislative responses to COVID-19 through war metaphors. Law and Humanities, 1-25.

Hall, R. B. (1999). National collective identity: Social constructs and international systems. Columbia University Press.

Hardey, M. (2002). 'The story of my illness': Personal accounts of illness on the Internet. Health: 6(1), 31-46.

Harrington, K. J. (2012). The use of metaphor in discourse about cancer: A review of the literature. Clinical Journal of Oncology Nursing, 16(4), 408416.

Jetly, R., Vermetten, E., Easterbrook, B., Lanius, R., \& McKinnon, M. (2020). Going to 'War': War Approach as the Antidote to Defeating COVID-19. War Behavioral Health, 1-5.

Jia, Y.J. (2015). 战争隐喻广泛性之理据分析[Analysis of the rationality of the universality of war metaphor]. Academics in China/学术界, (12), 148-153

Jobst, K. A., Shostak, D., \& Whitehouse, P. J. (1999). Diseases of meaning, manifestations of health, and metaphor. The Journal of Alternative and Complementary Medicine, 5(6), 495-502.

Kraska, P. B., \& Kappeler, V. E. (1997). Militarizing American police: The rise and normalization of paramilitary units. Social Problems, 44(1), 1-18.

Kirkman, A. M. (2006). Dementia in the news: the media coverage of Alzheimer's disease. Australasian Journal on Ageing, 25(2), 74-79.

Kothari, A. (2016). Signifying AIDS: How media use metaphors to define a disease. African Journalism Studies, 37(2), 19-39.

Lakoff, G., \& Johnson, M. (2008). Metaphors we live by. University of Chicago Press.

Larson, B. M., Nerlich, B., \& Wallis, P. (2005). Metaphors and biorisks: The war on infectious diseases and invasive species. Science

Communication, 26(3), 243-268. 
Li, H.T. (2014). 已结束的'战争'走不出的'迷宫'——SARS 十年'纪念报道中国的隐 喻运用与媒体记忆 [The Ended 'War' and The 'Maze' Cannot Get Out of The Use of Metaphors and Media Memory in the Commemorative Report of 'SARS Decade']. Journalists/新闻记者, (04), 86-95

Liu, H., Gao, P., \& Xiao, Y. (2018, June). New words discovery method based on word segmentation result. In 2018 IEEE/ACIS 17th International Conference on Computer and Information Science (ICIS) (pp. 645-648).

McCartney, M. (2014). The fight is on: War metaphors for cancer may harm patients. BMJ, 349, g5155.

Neilson, S. (2016). Pain as metaphor: Metaphor and medicine. Medical Humanities, 42(1), 3-10.

Nie, J. B. (1996). The physician as general. JAMA, 276(13), 1099.

Nie, J. B., Gilbertson, A., de Roubaix, M., Staunton, C., van Niekerk, A., Tucker, J. D., \& Rennie, S. (2016). Healing without waging war: Beyond war metaphors in medicine and HIV cure research. The American Journal of Bioethics, 16(10), 3-11.

Orgad, S. (2005). Storytelling online: Talking breast cancer on the Internet (Vol. 29). Peter Lang.

Parikh, R. B., Kirch, R. A., \& Brawley, O. W. (2015). Advancing a quality-of-life agenda in cancer advocacy: Beyond the war metaphor. JAMA Oncology, 1(4), 423-424.

Parsi, K. (2016). War Metaphors in Health Care: What Are They Good For?. The American journal of bioethics: AJOB, 16(10), 1-2.

Pihlaja, S. (2017). 'When Noah built the ark...': Metaphor and biblical stories in Facebook preaching. Metaphor and the Social World, 7(1), 87-102.

Radley, A. (2002). The role of metaphor in adjustment to chronic illness. In Worlds of IIIness (pp. 121-135). Routledge.

Reisfield, G. M., \& Wilson, G. R. (2004). Use of metaphor in the discourse on cancer. Journal of Clinical Oncology, 22(19), 4024-4027.

Rin, H. (1965). A study of the aetiology of koro in respect to the Chinese concept of illness. International Journal of Social Psychiatry, 11(1), 7-13.

Semino, E. (2008). Metaphor in discourse. Cambridge University Press.

Semino, E., Demjén, Z., Hardie, A., Payne, S., \& Rayson, P. (2017). Metaphor, cancer and the end of life: A corpus-based study. Routledge. 
Shao, P., Ye, S. (2020). 疫情报道中我们需要怎样的新闻与新闻业——兼论中国 建设性新闻理念的建构 [What kind of news and journalism do we need in the epidemic report__Also on the construction of China's constructive journalism concept]. Contemporary Communication/当代传播, (3), 76-88

Shi BY., Jiang LS., Pan YJ. (1982). 汉语惯用语简说 [A Brief Introduction to Chinese Idioms]. Language Teaching and Research/语言教学与研究, (4), 87-101

Sim, S. (2008). A meeting with Persephone. Illness, Crisis \& Loss, 16(4), 335344.

Sun, S.J., Wang, F., Liu, ZY., Tao, Y.Z. (2020). 新冠肺炎疫情语境中多元媒介的 微博话语表达 [Multi-media Discourse Expression of Multimedia in the Context of New Coronary Pneumonia Epidemic Situation]. Journalism Research/新闻大学, 03, 16-30+117.

Veith, I. (1997). The Yellow Emperor's classic of internal medicine: Chapters 134. (Translated from the Chinese with an introductory study). Pelanduk Publications.

Wallis, P., \& Nerlich, B. (2005). Disease metaphors in new epidemics: The UK media framing of the 2003 SARS epidemic. Social Science \& Medicine, 60(11), 2629-2639.

Weinstein, A. (2003). Afterword: Infection as metaphor. Literature and Medicine, 22(1), 102-115.

Wiggins, N. M. (2012). Stop using war metaphors for disease. BMJ, 345, e4706.

Wu, G. (1994). Command communication: The politics of editorial formulation in the People's Daily. The China Quarterly, 137, 194-211.

Xu, R.Y. (2013).传统媒体微博如何提高影响力一一基于对人民日报高转发量微博 的内容分析 [How to increase the influence of traditional media WeiboBased on the analysis of the content of People's Daily high-repost Weibo]. Journalism Practices/新闻实践. 3, 15-22

Yang, Y., \& Dong, F. F. (2017). 当代中国媒体话语中的战争隐喻现象研究 [Research on the metaphor of war metaphor in contemporary Chinese media discourse]. Foreign Language and Literature Research/外国语文研 究, 2, 2-11. 
Yang, Z. (2020). Military metaphors in contemporary Chinese disease coverage: a case study of the People's Daily, 1946-2019. Chinese Journal of Communication, 1-19.

Zhang, J.X. (2020). 把新冠病毒消灭还是与其共存? 张文宏给出他的判断 [Eliminate the new coronavirus or coexist with it? Zhang Wenhong gave his judgment]. Science and Technology Daily/科技日报, 09.03, A3

\section{Biography}

Zheng Yang is an Assistant Professor at the School of Communication, Soochow University, China. He has a PhD from the Department of Sociological Studies of the University of Sheffield, UK. His research interests include science communication, health communication, digital media and social.

\section{E.: zyang68@sheffield.ac.uk}

